\title{
THRESHOLD EFFECTIVENESS IN CONTRIBUTING TO THE PUBLIC GOODS: EXPERIMENTS INVOLVING CZECH STUDENTS
}

\author{
Jiří Špalek, Zuzana Berná*
}

\begin{abstract}
:
Voluntary contribution mechanism to public goods is one of the traditional types of economic experiments. The article summarizes the results of series of experiments that have been conducted with several groups of Czech university students. Using the threshold mechanism the impact of several factors (experience, communication and the form of experiment) on voluntary contribution to public goods is tested. The results confirm, to a great extent, findings published by foreign studies. The results show that Czech students also do not behave consistently with the traditional economic public goods model, i.e. they cooperate voluntarily in situations that favour free riding. Threshold is a traditional part of (mostly American) charitable collections and can be regarded as one of the most successful modifications of the voluntary contribution mechanism to public good. Experiments involving Czech students indicate that such technique can be successful even in Czech non-profit sector.
\end{abstract}

Keywords: experimental economics, public goods, threshold, game theory, charitable giving

JEL Classification: C72, D70, H41

\section{Introduction}

One of the traditional areas of study of experimental economics is voluntary contribution to public goods. There are many reasons for the popularity of experiments dealing with this issue. Key questions include the issue of the actual degree of free riding present in voluntary contributions. Do really people behave according to economic theory? Linking the results with practical application such as charity collections, respectively fundraising techniques used in them (especially in the U.S.A) ${ }^{1}$ is in this case also very interesting.

We have performed experiments based on the traditional scheme of voluntary contribution mechanism (VCM) - the so-called linear public good games. We have added

* Faculty of Economics and Administration, Masaryk University Brno, Czech Republic.

Acknowledgement: the authors wish to acknowledge the financial assistance of the MŠMT Project 2D06029 - "Distributional and Social Effects of Sectoral Policies" and the project of specific research at Masaryk University Brno "Actual Economic and Institutional Challenges for the Public Policy".

1 From the entire series of articles on this subject we can list, for example, the comparison of laboratory and field experiments by Benz, Meier (2008), who found a correlation in the behaviour of the same participants in both laboratory and field experiments. Analysis of three different variants of charitable collections in an experimental environment is shown by Huck, Rasul (2008). Using the treshold mechanism in charitable collections is discussed in Rondeau, List (2008) 
the threshold condition for the provision of public goods (sometimes called provision point or step-level public good) to the basic scheme. The inspiration for our experiments was an experiment published by Marks et al. (2003). However, since a similar pattern was used by a number of experimenters, ${ }^{2}$ our study is not a direct replication of that experiment. We adapted the experimental design to the hypotheses we studied. In addition to the basic question - what is the impact of the introduction of a threshold on the level of contributions, we were also interested whether the level of contribution rate is affected by the possibility of communication among participants, their experience with the economic experiment, or the nature of the experiment (computer versus face to face).

Our study thus summarizes mainly the results of several experimental sessions that we carried out in 2007-2009 with students of Masaryk University in Brno and University of Economics in Prague. Since one of the main hypotheses of our paper is devoted to examining the differences (similarities) in behaviour of Czech students compared to others, we also compared the recently published results of experiments involving Slovak students, carried out by colleagues from the Technical University in Košice (see Bačo, Horváthová, Gazda, 2008). We believe that our contribution adds some additional characteristics to the results presented by them. Our results are also based on a larger sample of test subjects. However, as we will show further, we are in agreement with the basic conclusions of the experiments of our Slovak colleagues.

\section{Experiments Dealing with Public Goods}

Public goods and in particular the voluntary mechanism belong to the traditional areas of economic experiments. As pioneer works in this field are undoubtedly considered articles by Marvell and Ames $(1979,1980)$, which considerably weakened the traditionally accepted conclusion of the theoretical model. Subjects who participated in the experiment, where a situation of contributing to public good was modelled, in most cases did voluntarily contribute to a public goods. As the results of further experiments showed - especially Isaac, McCue and Plott (1985) - change in conditions of the experiment weakens, to a certain point, the conclusion of the Marvell and Ames' experiments. In particular, repeating the given situation brings almost certainly higher level of free riding than in case of one-shot game.

A number of other experiments followed-up on these works later and resulted in a fairly extensive knowledge about the structure of the factors that influence the rate of free riding. These factors may, up to a certain point, determine the appropriate area for the use of the mechanism of voluntary contributions to public goods, and therefore may have associated economic and political consequences. ${ }^{3}$

2 Summary of experiments carried out up to 1995 is presented by Ledyard (1995), more recent experiments using meta-analysis are summarized by Zelmer (2003), experiments examining the conditional cooperation are summarized by Chaudhuri (2008). Besides these reports, results of experiments with public goods can be found in Plott, Smith (2008).

3 Charitable collections are considered an example of the use of traditional mechanisms of a voluntary contribution to public goods in practice. Threshold mechanism is then be one of the typical applications suitable for the modification of a charitable collection - see, e.g. Rondeau, List (2008). Similarly, a potentially interesting modification is the concurrent use of providing of public and private good through charitable lottery (Dale, 2004), or the analysis of using the mechanism as a punishment for tax offenses. 


\subsection{Previous Findings of Experiments Dealing with Public Goods}

The first and oldest group of experiments aimed to find a typical level of public goods provision in terms of the voluntary contribution mechanism (the VCM). These experiments sought to answer the question how much of public good is provided in terms of VCM, or how much people are willing voluntarily contribute for public goods. As shown for example by Davis, Holt (1993), the usual rate of contribution is considered to be between $40-60 \%$ of the maximum group total contributions in the first round of the game, with the proportion decreasing in subsequent rounds.

The experiments performed so far have shown that it is possible to specify a "usual range" of contribution level to public goods. The very existence of the range suggests that the level of voluntary provision can be affected not only stochastically but also systematically. For these reasons, the experimenters were largely interested in those characteristics that have positive or negative effect on the given value. The first overview of the characteristics affecting the rate of voluntary contributions to public goods was published by Ledyard (1995). Ledyard divides these factors into three following groups: ${ }^{4}$

- Environmental factors (for example number of participants, the degree of economic profitability of free riding (the so called $\mathrm{MPCR}^{5}$ ), the rate of recurrence of the situation or gender).

- Personal factors (economic education, risk aversion, beliefs, innate altruism, experience, learning effect, identification of oneself with a group).

- Factors associated with the nature of the experiment (factors defining the particular form of the environment and the mechanism: the possibility of communication or punishment).

The above stated factors were further explored by a number of experimenters. The influence of most of the factors can be considered as proven. The results of more recent experiments and detailed overview of the impact of the above factors including the expression of their extent are indicated by Zelmer (2003). Unlike Ledyard's analyses, a meta-analysis of the results of experiments conducted by him revealed no significant effects of economic education ${ }^{6}$ on the level of contribution, similarly for the number of participants in the experiment or their gender. Zelmer's meta-analysis did not even demonstrate any significant effect of repetitions, although it is also clear from the analysis that the rate of contribution is decreasing with repetitions.

The above presented experiments and their results have essentially predetermined the further development of VCM research. Although some of the characteristics (factors) can be currently considered to be demonstrably significant and affecting the

4 Exhaustive list of factors is provided by Ledyard (1995).

5 Marginal Per Capita Return (MPCR) or marginal per capita income is the ratio of profit from one payment unit invested in public goods and the opportunity cost of investing of that unit. For more explanation of the concept see for example Davis, Holt (1993)

6 The effect of economic education on the contribution level is discussed by for example Frank et al. (1993). Their results suggest that students with economical background contribute less than students of other majors. Contradicting opinion is provided by Yeezer et al. (1996), who question results published by Frank. This hypothesis is within the Czech environment studied in by Šeneklová, Špalek (2009). Their results are in line with conclusions in Frank et al. (1993). 
level of voluntary contributions to public goods, the majority of them do not offer direct possibility to adjust (increase) the resulting level of provision. ${ }^{7}$ For these reasons a large part of current study in the field of $\mathrm{VCM}$ is directed to find and assess the effectiveness of modifications or alternatives to the traditional VCM.

\subsection{Threshold for Providing Public Goods}

Our experiments have primarily focused on the effectiveness of one of these modifications - the so-called threshold provision of public goods. One of the reasons was the fact that the threshold mechanism (or provision point) is used quite often as typical instrument in practice of (especially American) fundraisers. ${ }^{8}$ The introduction of the necessary minimum of contributions collected for the provision of public goods is stimulating for voluntary contributions to charity (which are similar to voluntary contributions to public goods). The form of the threshold in these cases is usually in the nature of certain sum of money that must be collected at the minimum, for the goods to be provided (for example covering the necessary fixed costs of the charity program or project).

In the standard VCM model entitlement to a contribution from a group account (i.e. the right to use public goods) is automatic. Each member of the given community (test group) gets to claim the public goods regardless of whether he contributed to the public goods or not. ${ }^{9}$ A threshold, however, makes this automatic right to claim conditional. The condition for payment of proceeds from contributions to public goods (i.e. consumption of a public good) is certain minimum amount of funds, known as the threshold or a provision point that must be collected within the VCM. In the event that such threshold of contributions is not reached experimenters offer two basic mechanisms of further behaviour: in the first case, the funds given for public goods are considered lost and contributors will not be refunded. Or, as it was the case in our experiments, participants in the VCM mechanism with threshold are ensured that if there are not sufficient funds contributed to the public good, the funds will be returned to the contributors.

According to economic theory in the case of the standard VCM (no threshold conditions) there is only one equilibrium corresponding to the dominant strategy: not to contribute to public goods. ${ }^{10}$ In contrast, in the case where a threshold is present

7 It is not possible in all situations to change the advantage of free riding (or disadvantage of contributing) using the MCPR. Similarly it is not often times possible to change the frequency of repeating a given situation.

8 Bagnoli, McKee (1991) provide an example of successful collection of a Canadian political party that wrote to its supporters a letter requesting assistance. The letter was accompanied by assurances that if the collection does not bring more than $200000 \mathrm{CAD}$ the party promises to return the contributions.

9 The exception is of course a situation that would correspond to the theoretical solution of a given situation - that is a situation when nobody has contributed to a public good and therefore a public good is not provided.

10 Considering only two players, standard VCM can be modelled as the so-called Prisoner's dilemma, where each player makes his decision whether to contribute to a public good or not. The dominant strategy of both players in this case is not to contribute to the public good and the game results in single Nash equilibrium corresponding to a situation where no one contributes anything (and the public good is not provided). See, for instance, Davis, Holt (2003). 
(with a guarantee of reimbursement) two types of Nash equilibriums occur: The first one - a group of inefficient Nash equilibriums where the threshold is not reached and the public good is not provided. The second one - a group of efficient equilibriums corresponding to a situation where the threshold is just reached, a public good is provided, and the entire group behaves efficiently. Number of such equilibria increases with the number of participants. Since, in general, each of the participants can contribute in a given situation with a different amount, Nash equilibrium is composed by the vector of individual contributions where the threshold is reached exactly and the sum of contributions equals the costs of a public good (and where none of the individuals contributes more than his own valuation of the public good is). ${ }^{11}$

Expressed mathematically, the equilibrium vectors must satisfy two following conditions (according to Croson, Marks, 2000):

condition of efficiency

and the condition of individual rationality:

$$
\begin{aligned}
& \sum_{i} \sigma_{i}=K, \\
& \sigma_{i} \leq v_{i} \forall i,
\end{aligned}
$$

where $K$ is the cost of providing the public good (threshold level), $\sigma_{i}$ is a contribution of a player $i$ to a public good and $v_{i}$ is individual valuation of the given public good by the player $i$.

Performed experiments ${ }^{12}$ do, to a large extent, confirm the legitimacy of the given statement. In the case of repeated game it is possible to observe the convergence of the sum of contributions to the threshold limit, and therefore to the (efficient) Nash equilibrium. However - based on the theory developed by Bagnoli, Lipman (1989) - that does not mean that a free riding behaviour is missing. The theory merely says that with the gradual increase in the threshold it is possible to expect an increase in contributions, provided that the threshold is lower than the overall benefit of potential contributors. In this context, we wanted to know whether, under the above assumptions, Czech students also behave this way. Thus the first hypothesis was:

H1: The introduction of threshold makes contributions to public good converge (in a repeated game) to Nash equilibrium with sum of contributions equal to the threshold level.

We tested this hypothesis using comparison of the results of our experiments and results of previously performed experiments. We were, above all, inspired by the meta-analysis referred to in Croson, Marks (2000). Although the authors are primarily dealing with the effect of the changing rate of substitution between the contribution to private and public account, ${ }^{13}$ the effect of some factors we studied (communication, guarantee of reimbursement in case of the failure to meet the threshold) can also be found there. Since this is a meta-analysis of other experiments,

11 It is therefore not required that all contribute equally. It is, however, important that the contributions of those contributed less are compensated by others who have contributed more.

12 For example, the results of laboratory experiments mentioned by McBride (2004) or Bagnoli, Lipman (1992). Comparison of laboratory and field experiments with threshold mechanism can be found in Rodeau, List (2008).

13 Unlike the linear VCM where this ratio is called the MPCR, Croson, Marks (2000) used the term step return (SR). Their study suggest the values of SR ranging from 1.2 to 9.5 . 
the given source also gives us convenient opportunity to compare the results. ${ }^{14}$ Besides the above hypothesis, our experiments focused as well on some factors affecting the rate of contribution to public good in the case of presence of a threshold. In this context, we stated the following hypotheses:

H2: Communication always increases the rate of contribution regardless of the moment at which it is permitted.

H3: Computer form of the experiment, where the players do not see each other and their interaction is thus less "personal", reduces the level of contribution.

H4: Participants in the experiment who have already participated in similar experiment will behave less cooperatively than the "newcomers". ${ }^{15}$

Besides these factors we also studied the influence of other potential effects (such as gender, or education in economics). However, because of the limited space, we do not publish these results in this article. ${ }^{16}$

\section{The Experiment}

As already noted, the experiments we carried out cannot be considered as direct replication of other experiments; nevertheless their form is largely based on them. Our inspiration was mainly an experiment published in Marks et al. (2003). Compared to their experiment, we made some partial changes. In particular we used the option to invest only two tokens contrary to the 25 tokens used by Marks et al. (2003). The presented results are based on two basic experimental designs:

- Experiment studying the effects of the threshold on contribution rate (groups MU07, MU08, ESF07, and ESF08)

- Experiment studying the effect of certain factors on contribution rate in the presence of the threshold (groups MU09, VSE1, and VSE2 ${ }^{17}$ ).

The participants of our experiments were students from various faculties of Masaryk University in Brno (MU) and students of the University of Economics in Prague (VSE). In the case of MU, we recruited participants through advertisements on the university's electronic bulletin board saying that we are looking for volunteers for an economic experiment. Students knew in advance that we would observe their behaviour in certain model situation (of course they did not know which economic model it would be) and that they would receive money reward depending on their behaviour.

Participants in the experiment conducted at VSE were students of various faculties of this university attending courses on Public Finance. Experiments were carried out within the coursework of this class, and students were financially motivated in this case as well.

14 Our experiments are not a direct replication of other specific studies, but were merely inspired by them. For these reasons we do not compare specific level of contribution, but we are rather interested in general trends and their consistency with other experiments.

15 This hypothesis is trying to capture the so called learning effect.

16 We refer to other publications: Špalek et al. (2008), Šeneklová, Špalek (2009), Berná, Špalek (2009).

17 Abbreviations describing the groups will be explained in further text. 


\subsection{Experiment Studying the Effects of the Threshold Introduction on Contribution Rate}

The experiment was carried out as a repeated game. Participants completed a total of 12 rounds, with the first six rounds being a classic VCM and only the second half of the experiment involved the use of threshold.

The experiment was conducted in four groups of approximately 42 persons:

- Two sessions within the course offering at the MU Faculty of Economics and Administration (denoted as ESF07, ESF08)

- Two sessions for students of all Masaryk University faculties (MU07, MU08)

Since only participants of MU07 and MU08 sessions were financially motivated, ${ }^{18}$ the conducted experiments allowed us to also compare the effect of financial incentives on individual behaviour.

The basic form of the experiment was based on the traditional repeated VCM game. Within each of the 12 rounds the participants had to decide between contributing to personal and a group account. In each round they disposed of two tokens. Personal account profit was fixed, while the group account profits depended on the total amount of contributions. The total income per player (in CZK) per round can be described by the following equation (3), where

$$
z_{i_{j}}=\left(2-y_{i_{j}}\right)+\frac{1}{4} \sum_{n=1}^{N} y_{n_{j}}
$$

$z_{i_{j}}$ is the profit of the $i$-th player in the $j$-th round

$y_{i_{j}}$ is the deposit of $i$-th player to the group account in the $j$-th round

$y_{n_{j}}$ is the deposit of $n$-th player to the group account in the $j$-th round;

$N$ is the number of players

Therefore, the profit from the group account at the rate of $1 / 4$ of the total amount of collected tokens is added to tokens the player kept (each token having a value of CZK 1). At the end of the experiment total sum of amounts earned during twelve rounds was paid out to the players.

A threshold guaranteeing the return of funds was introduced after the sixth round. The threshold level was set at minimum amount of 40 tokens. In case that this amount was not collected in the group account, the funds were returned to the individuals, respectively transferred to the personal account.

\subsection{Experiment Studying the Effect of Communication and Types of Experiment}

The second experiment was carried out in 2009 in three groups (sessions) - MU09, VSE1, and VSE2. The players were financially motivated in all three groups of about 30 persons.

18 The second - control - group was motivated only indirectly. These were students of one of the courses devoted to the theory and practice of state intervention, and the given experiment was part of the exercises from this course. Students were motivated in a way that is traditionally recommended in the literature (for example Brock, 1991) rather than financial reward, one (randomly selected) participant was awarded points necessary to complete the course, in the rate that corresponded to the amount won by him. 
As already noted, the basic scheme of VCM has been examined in fairly detailed way. The meta-analysis by Zelmer (2003) provides a clear idea about how contribution rate is influenced by the modification of certain factors. For this reason we also changed several factors in each of the three sessions. We wanted to know whether the reaction of Czech students to this change would be in line with international results.

Both groups VSE1 and VSE2 had the same initial basic scheme (see above) and the so-called "face-to-face" 19 form, in other words, there was a personal interaction among the players. After the third round a change occurred in the profitability of the personal account - in other words change in $\mathrm{MPCR}^{20}$ - for the VSE1 group. The change meant that they received only CZK 0.50 from a token kept (not invested in the group account). The player's modified profit per round is expressed by the following equation (4):

$$
z_{i_{j}}=\frac{1}{2}\left(2-y_{i_{j}}\right)+\frac{1}{4} \sum_{n=1}^{N} y_{n_{j}}
$$

MPCR was returned to its original value after the sixth round. At this point, a discussion among the players was allowed. The players could communicate with each other and agree on further (mutual) strategy for the remaining three rounds.

In the second group (VSE2) the profitability of the personal account remained at the same level (corresponding to Equation 1) throughout the experiment. After the third round, the players were allowed to agree on a mutual strategy for the remaining rounds. After the sixth round a threshold of CZK $30^{21}$ was introduced to the game as the minimum amount that had to be collected in the group account (so that the profit would be paid out of the account). In case the threshold was not reached, all of the money was returned to the personal accounts of the players.

The experiment for the MU09 group was computerized. ${ }^{22}$ The initial scheme was consistent with the other two groups (VSE1 and VSE2). The only modification in the course of the game was the introduction of CZK 30 threshold after the sixth round. (The failure to reach the threshold meant that all of the money was returned to players' personal accounts, as in the case of VSE2 group).

\section{Results and Discussion}

We will focus, in accordance with hypotheses stated, on several questions: we were interested in the overall contribution rate of Czech students to a public good, their reaction to the introduction of a threshold, and the effect of several other selected factors on the contribution rate in terms of the presence of a threshold.

19 Sometimes they are referred to as Hand-run experiments. See for example Becker, Watts (2006).

20 The reason for this modification was to find out whether the subject would react to the lowering of the profits of the personal account by increasing their contribution to the collective account as it had been shown by experiments testing the effect of changes to MPCR carried out so far. See for example Holt (2007).

21 The threshold limit used by us corresponds to SR (step-return) value 2 - which, as Croson, Marks (2000) indicate is the most often used value. SR value around $2(\mathrm{SR}=2.1)$ was also used in the above described experiment involving 42 students.

22 The experiment was carried out using z-Tree software. This is freely available software designed especially for economic experiments by Zurich University. For more see Fischbacher (2007). 


\subsection{Total Contribution Rate}

As far as the behaviour of Czech students in general under VCM is concerned, we can state that the results we obtained are consistent with findings from experiments carried out to this point. In our experiment the Czech students actually voluntarily contributed to a public good, even if it contradicts their dominant strategy not to contribute. This was even a very significant phenomenon in both sessions of the MU experiment. As shown in Figure 1, in the case of both MU experiments the amount of points deposited to the group account did not decrease below $50 \%$ in any of the rounds.

Although the free riding does occur in this situation it can be seen that this behaviour is not prevailing. Czech students, similar to their foreign counterparts, do voluntarily contribute to public goods, even if their reason tells them not to contribute. On the other hand, the contribution rate is under the efficient level.

In agreement with the traditional methodology of economic experiments the earnings were adjusted to reflect the average hourly earnings. Actual earnings varied of course in each treatment depending on the actual behaviour of players. The participants in both twelve round experiments earned the highest average earnings - MU07 (405 CZK) and MU08 (348 CZK). If we were to pay participants in learning experiments carried out at ESF MU using real money, their earnings would have been lower ESF07 (190 CZK) and ESF08 (266 CZK). In nine-round experiments the average earnings were lower - MU09 (70 CZK), VSE1 (71 CZK) and VSE2 (99 CZK).

\subsection{Reaction to the Introduction of the Threshold for the Provision of Public Goods (Hypothesis H1)}

Threshold is considered to be a so-called strong factor ${ }^{23}$ that increases the rate of voluntary contribution to public good. This fact was clearly demonstrated in all four sessions. A threshold was introduced always in the seventh round and in all four test groups the rate of contribution increased substantially. The effect can be seen even in the two groups of MU experiment where contributions to the group account in the first six rounds (before the introduction of a threshold) were higher than the threshold and thus did not require any change in behaviour of participants after the introduction of a threshold.

The second effect related to the threshold - achieving Nash equilibrium in terms of such total group contribution that the threshold level is just reached - was strongly present only in two groups (MU08 and ESF08). The ESF08 group corresponded most to the model where convergence to the threshold limit can be gradually seen beginning with the seventh round (see Figure 1). In this respect, we cannot reject hypothesis H1.

It beckons to compare the results of our experiments with the experimental results described by Baco, Gazda, Horváthová (2008). A threshold of $65 \%$ of the maximum possible amount collected was set in their study, while the subjects in case of failing to meet the threshold for the provision of public goods lost their deposits. So, if subjects contributed to this collective good, they undertook a higher risk in comparison with our experiment. In the first group, the required minimum level was reached only twice in 10 rounds, we could, however, observe the average contributions to the collective good getting closer to an efficient Nash equilibrium corresponding to the threshold level.

23 See Ledyard (1995). 
Figure 1

Average Contribution to the Group Account by Different Groups

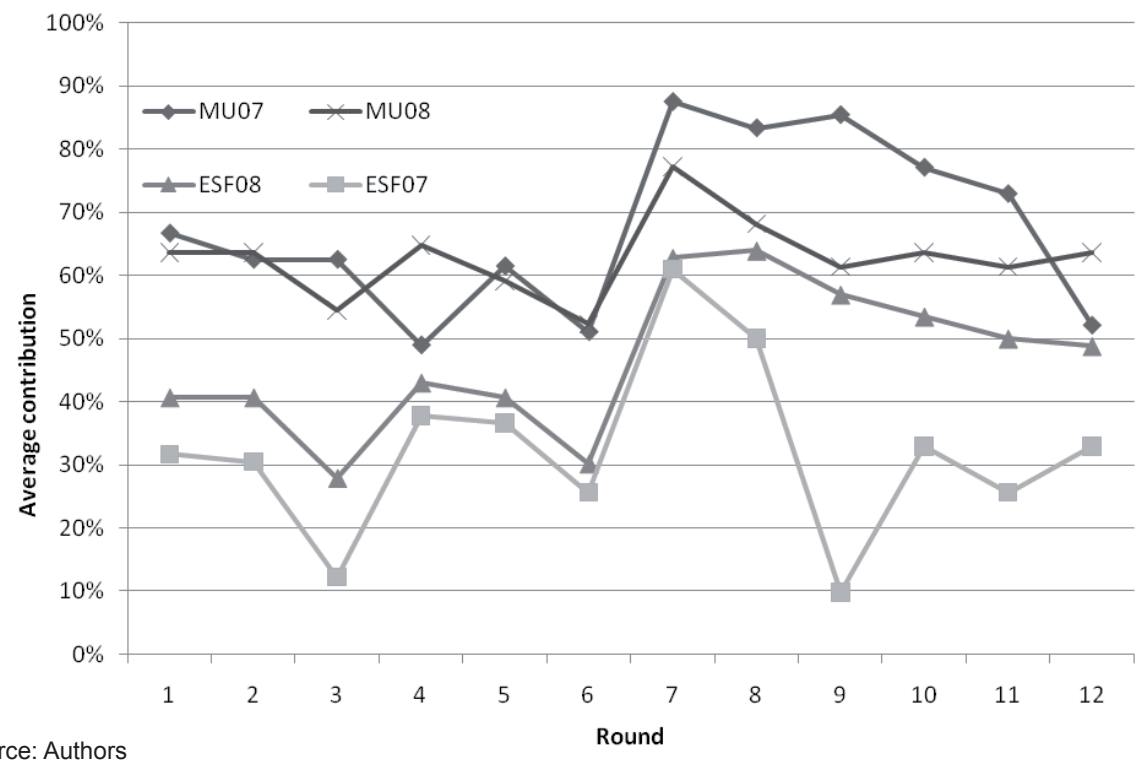

Source: Authors

This was consistent with our results. In the second group, however, the threshold was not reached even once, and the average contribution to the collective good was with repeating rounds approaching the "original" Nash equilibrium, that means a zero contribution. The given disparity between this group and our results can be explained precisely by setting the (no) return mechanism.

\subsection{Communication among Subjects (Hypothesis H2)}

We tested the effect of the possibility to communicate among participants in the experiment involving the VSE group. In VSE1 group participants were allowed to agree on further mutual strategy after the sixth round and the VSE2 group after the third round of the experiment. In addition to the impact of the possibility of agreeing on a common strategy, we also wanted to know whether the "timing" of allowing the discussion had an effect on the behaviour of participants.

In both cases permitting communication between participants resulted in increase of the average contribution to the group account (in case of VSE1 29\% increase and $40 \%$ increase for VSE2 group). However, this increase was not permanent and in the subsequent rounds the decline in average contribution to the group account occurred again. ${ }^{24}$ It is also, among other things, the result of a phenomenon we call "the

24 The impact of communication on the contribution level we study in teaching experiments at ESF MU as well. Students are not financially compensated for their participation they earn points necessary for completion of the study course. Despite that, the results are simile to those presented in this paper. The agreement on mutual progress usually played an important role in the contribution level. This agreement falls however apart within a short period of time. It is interesting to note that women are more inclined to punish the failure to adhere to the agreement in these experiments. For more see Špalek et al. (2008). 
disappointment effect": the subjects agree during their discussion that all of them will contribute all their endowment to the group account, which will result in the maximum possible amount to be distributed among them. However, when the total sum of contributions in particular round was announced it was apparent that some participants failed to adhere to the agreement. This may have, for some of the players who actually contributed their entire endowment, caused disappointment and the desire to "punish" the others by contributing less or nothing in the next round. ${ }^{25}$

Observed results show that facilitating cooperation between the players always leads to an increase in contribution rates to the public good regardless of when it is permitted. Although we can confirm hypothesis H2, it is clear, that one-shot communication does not provide a permanent solution.

\subsection{Computer vs. Face to Face Experiment (Hypothesis H3)}

We used the results of the two experiments - "computer" group (MU09) and "face to face" group (MU08) - to confirm or to refute the hypothesis H3 saying that the computerized form of the experiment, where the players do not see each other and the interaction is less "personal", reduces the level of contribution. ${ }^{26}$ We compared data from the first nine rounds of these experiments. The behaviour of subjects in these two experiments can be seen in Figure 2.

Figure 2

Average Contributions to the Group Account Using Computer and Face to Face Experiment

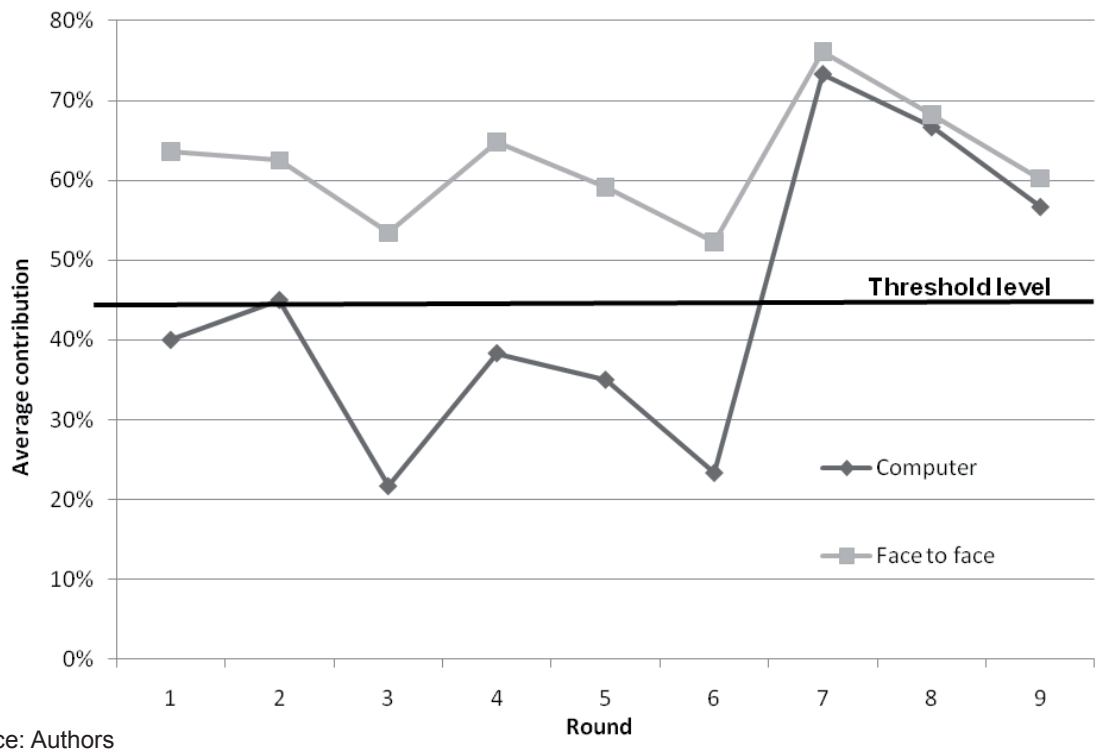

Source: Authors

25 Some of the participants indicated these motives in the post experiment discussion.

26 Both experiments were similar (participants had the same disposable pension, communication was prohibited, the threshold was introduced after the sixth round), they differed only in the number of rounds (MU 08 - 12 rounds, MU 09 only 9 rounds). The participants in the MU09 experiment were not however informed that round 9 is the last round, they expected the experiment to continue with additional rounds. 
In the first six rounds a significant difference in average contributions to a group account between the two groups can be observed. The difference equals $25 \%$ on average. The behaviour of subjects in the first six rounds thus supports hypothesis H3.

There is an interesting change in behaviour after the introduction of a threshold. Both groups react to this by increasing contributions in such proportions that the new average amount of contributions is approximately at the same level. We can observe, for both groups, a convergence of contributions to the group account (public good) to Nash equilibrium corresponding to the threshold level.

\subsection{Participants' Experience (Hypothesis H4)}

The participants were asked to fill out a questionnaire at the conclusion of the MU09 computer experiment. They were asked, among other things, whether they had participated previously in an economic experiment. One third of subjects asked replied affirmatively. ${ }^{27} \mathrm{We}$ observed interesting results by comparing the behaviour of these participants with the behaviour of those who participated in the experiment for the first time. "Experienced" participants contributed on average of $11 \%$ less than their inexperienced counterparts in all rounds of the experiment. Average contributions in individual rounds are presented in Table 1.

Table 1

Average Contributions by Experienced and Inexperienced Participants to Group Account

\begin{tabular}{|l|r|r|r|r|r|r|r|r|c|}
\hline \multicolumn{1}{|c|}{ Average contribution to group account (in \%) } \\
\hline Round & 1. & 2. & 3. & 4. & 5. & 6. & 7. & 8. & 9. \\
\hline Experienced participants & 32 & 36 & 8 & 32 & 18 & 18 & 64 & 50 & 50 \\
\hline Inexperienced participants & 40 & 45 & 26 & 38 & 40 & 24 & 71 & 69 & 55 \\
\hline
\end{tabular}

Source: Authors

The obtained results speak in favour of confirming our hypothesis H4 - more experienced players cooperate significantly less than "newcomers".

Even more interesting was to observe the influence of experience on players' strategy. Figure 3 shows five types of strategies the participants followed in the first six rounds of the experiment (that is before the introduction of a threshold). Depending on the amount of the average contribution to the group account, we labeled the strategies as follows:

- Pure free-rider strategy (never contributes anything);

- Partial free-rider strategy (contributes 2 tokens at max in total);

- A mixed strategy;

- Partial altruist strategy (does not contribute 2 tokens max in total);

- Pure altruist strategy (always contributes everything to the group account).

As it can be observed in Figure 3, there were no pure or partial altruists among the experienced players. Again, this suggests a lower co-operation of experienced players.

27 This is mainly because experiments are part of traditional teaching at the ESF MU. 
It is also worth noting the behaviour of experienced players following the introduction of a threshold. Their average contributions to the group account reached the efficient Nash equilibrium already in the second round after the introduction of the threshold and they did not divert from this strategy till the end of the experiment.

Figure 3

Strategies of Players in the ESF PC Experiment, after the Implementation of the Threshold (1 to 6 Round)

Source: Authors

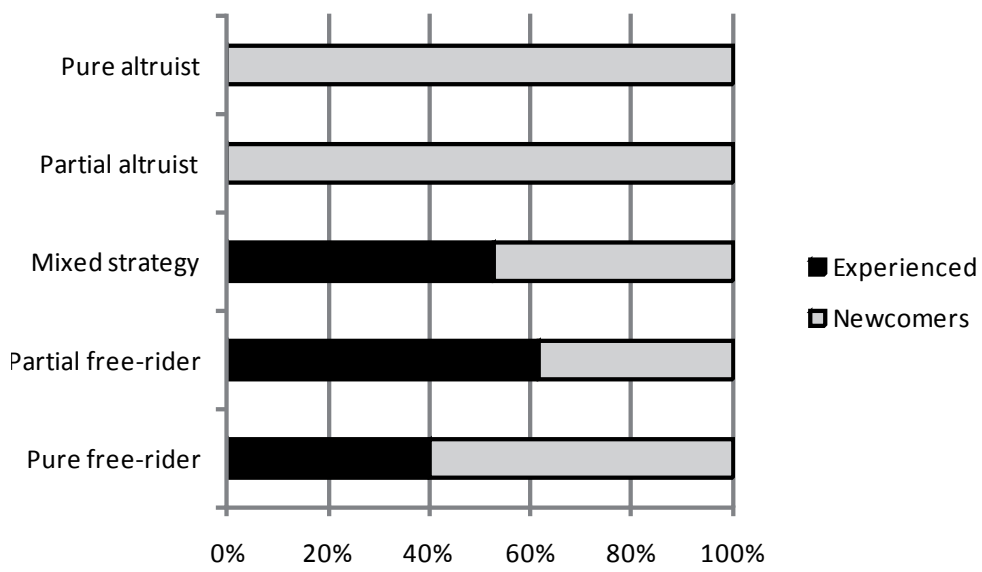

\section{Conclusion}

Theory dealing with public goods is so imbued with number of normative, or pseudo positive opinions that entering a fairly clear and positive scientific method, which in our opinion economic experimentation is, may be beneficial. The results of experiments conducted to present date confirm this assumption. Already the first experiments showed that it is impossible to provide an unequivocal answer to the fundamental question whether free riding is just a theoretical construction, or it is a typical behaviour of individuals in terms of voluntary contributions to public goods.

As shown by the results of our experiments involving Czech students, it can be considered as proven that people in a situation that allows free riding do, to a large extent, take advantage of this behaviour. On the other hand, we may confirm as well that this type of behaviour is not as dominant, as the theoretical assumptions would suggest. Although the quantity of public goods provided on voluntary basis is not efficient (or socially optimal), it is neither at zero level. People therefore do, up to a certain extent, voluntarily contribute to public goods.

Our experiments studied effectiveness of the threshold introduction into standard voluntary contribution scheme. The existence of a threshold is usually said to be strong incentive for people to increase their contributions. The results of our experiments with Czech students confirm to great extent this statement. Introduction of a threshold had positive impact on voluntary cooperation of Czech students (and thus reduction of their free riding). According to our results (and Slovak ones) it is clear that this mechanism is particularly effective in conjunction with a guaranteed reimbursement of contributions. It is no coincidence that this mechanism belongs to one of the most 
successful of practically used modification mechanism in voluntary contribution to public goods. A threshold is a traditional part of a wide range of (mainly) U.S. charity collections. Experiments involving Czech students showed that similar technique could be successful in Czech or Central European conditions.

In addition to the impact of introducing a threshold for voluntary contributions to public goods, we were interested in the effect of other selected factors on the contribution rate. Our results showed that permitting communication among the players increases their level of cooperation and their contribution to public good. However, it is not a permanent solution. Lower level of cooperation between the participants in the experiment can be expected if the subjects make their decisions using a computer terminal, and when there is no personal contact (as it is in the case of face to face conducted experiments). Participants' experience also has a negative effect on the level of public good contributions which is probably due to the "learning effect". The conclusions stated above suggest, to some extent, that the actual behaviour of subjects (in real conditions) in case of repeated decision making about a contribution to the public good may be more cooperative than it is indicated by the results of the experiments. We can consider this fact as one of possible explanations of the relative success of charitable collections based on a purely voluntary contribution principle.

\section{Appendix 1 \\ Instructions for Experiments MU07, MU08, ESF07, and ESF08}

Please follow these rules:

- Do not talk during the game. Do not give any indication about your decision, not even to your nearest neighbor. Do not consult your strategy.

- If you have a question, raise your hand and wait for the arrival of one of the staff (do not ask out loud).

\section{Game rules}

The game has 12 rounds. In each round you have 2 points available to distribute between "personal" and "group" accounts. The value of the deposited point varies depending on whether you deposit it to personal or group account (For details see Playing the game section). Your goal is to accumulate the highest aggregate amount (for all rounds).

You will be handed out 24 ballots (two for each round of the game). Indicate on each card whether you want to deposit to the group account (marked by a cross) or to the personal account (blank card). In a given round, you can:

Deposit both points to a personal account (two blank cards)

- Deposit one card to the personal and one to the group account (one blank card and one card with a cross)

- Deposit both to the group account (both cards marked with a cross). 
We will collect two ballots from you in each round. Hand over the tickets by placing them face down on the desk - so that nobody can see your decision.

You will record your decision throughout the game in the record sheet. You will also record your earnings in the individual rounds in the record sheet. By adding the amounts you will get the total amount per round as well as the total amount recorded. Nobody should be able to see your register throughout the game! Please hand in the record sheets at the end of the experiment.

\section{Playing the game}

The game consists of two blocks, 6 rounds each.

\section{1st block (Round 1 to 6)}

Each point deposited to the personal account is worth $2 \mathrm{CZK}$ (that means if you deposit in a given round two points to the personal account, you will have $4 \mathrm{CZK}$ ).

Your profit from contributing to the group account (in the amount of one or two points) is calculated as follows: after each round we will total the number of points that all of the players have deposited to the group account. Half of the total number of points is the amount in CZK that each player will receive, regardless of whether they contributed to the group account or not. At the end of each round we will announce the total amount deposited to the group account and you will record it in your record sheet.

\section{Calculation of earnings (in CZK) per player per round:}

Profit from the personal account (2 times the number of points you invested in the personal account)

$$
+
$$

Profit from the group account ( 0.5 times the number of all points invested in the group account)

\section{2nd block (Round 7 to 12)}

The terms remain unchanged for the personal account. The terms for paying profits out of the group account have changed. Your profit (in CZK) from the group account is again given by half of the total number of points that all players have saved in the group account. However, you are in this case entitled to this sum only if at least $\mathbf{4 0}$ points are deposited to the group account.

You are not entitled to this sum otherwise. The contributions to the group account are however not lost, they are only transferred back to your personal account. In other words, you will get in, a given round, the sum of CZK 4, as if you would have saved all points to the personal account.

At the end of the game you will receive the amount you have recorded during the experiment. In other words, the amount that is the sum of your earnings for each round.

The amount will be paid in cash at the end of the experiment. 


\section{Appendix 2 Instructions for experiments MU09, VSE1, and VSE2}

Please follow these rules:

- Do not talk during the game. Do not give any indication about your decision, not even to your nearest neighbor. Do not consult your strategy.

- If you have a question, raise your hand and wait for the arrival of one of us (do not ask out loud).

\section{Game rules}

The game has 9 rounds. In each round you have 2 tokens available to distribute between "personal" and "group" accounts. The value of the deposited token varies depending on whether you deposit it to personal or group account (For details see Playing the game section). Your goal is to accumulate the highest aggregate amount (for all rounds).

In a given round, you can:

- Deposit both tokens to a personal account (two blank cards)

- Deposit one token to the personal and one to the group account

- Deposit both to the group account

We will collect two ballots from you in each round. Hand over the tickets by placing them face down on the desk - so that nobody can see your decision.

Divide the tokens so that in the program you will indicate the number of tokens (using numbers 0,1 , or 2 ) you want to deposit to the group account (the remaining tokens remain in your personal account).

VSE1 + VSE2: You will be handed out 18 ballots (two for each round of the game). Indicate on each card whether you want to deposit it to the group account (marked by a cross) or to the personal account (an empty ballot). In each round we will collect two ballots from you. Hand over the ballots by placing them face down on the deskso that nobody can see your choice.

\section{Playing the game}

\section{Round 1 to 6}

Each token deposited to the personal account is worth $2 \mathrm{CZK}$ (that means if you deposit in a given round two points to the personal account, you will have $4 \mathrm{CZK}$ ).

Your profit from contributing to the group account (in the amount of one or two tokens) is calculated as follows: after each round we will total the number of tokens that all of the players have deposited to the group account. Half of the total number of tokens is the amount in $\mathrm{CZK}$ that each player will receive, regardless of whether they contributed to the group account or not. At the end of each round we will announce the total amount deposited to the group account. 


\section{Calculation of earnings (in $\mathrm{CZK}$ ) per player per round:}

Profit from the personal account (2 times the number of tokens you invested in the personal account)

$+$

Profit from the group account (0.5 times the number of all tokens invested in the group account)

\section{Round 7 to 9}

The terms remain unchanged for the personal account. The terms for paying out profits out of the group account have changed. Your profit (in CZK) from the group account is again given by half of the total number of tokens that all players have saved in the group account. However, you are in this case entitled to this sum only if at least 30 points are deposited to the group account.

You are not entitled to this sum otherwise. The contributions to the group account are however not lost, they are only transferred back to your personal account. In other words, you will get, in a given round, the sum of CZK 4, as if you would have saved all points to the personal account.

At the end of the game you will receive the amount you have recorded during the experiment. In other words, the amount that is the sum of your earnings for each round.

The amount will be paid in cash at the end of the experiment.

\section{References}

Andreoni, J. (1988), "Why Free Ride? Strategies and Learning in Public Goods Experiments." Journal of Public Economics, Vol. 37, No. 3, pp. 291-304.

Bačo T., Gazda V., Horváthova L. (2008), "Správanie spotrebitel'ov pri obstarávaní skupinového statku." Ekonomicky časopis. Volume 56, No. 6, pp. 551-564.

Bagnoli, M. Mckee, M. (1991), "Voluntary Contribution Games: Efficient Private Provision Of Public Goods." Economic Inquiry, 29 (2), pp. 351-366.

Bagnoli, M., Lipman, B. L. (1989), "Provision of Public Goods: Fully Implementing the Core through Private Contributions." Review of Economic Studies, 56(4), pp. 583-601.

Bagnoli, M., Lipman, B. L. (1992), "Private Provision of Public Goods Can Be Efficient." Public Choice, Springer, 74(1), pp. 59-78.

Benz, M., Meier, S. (2008), "Do People Behave in Experiments as in the Field? - Evidence from Donations." Experimental Economics, Vol. 11, No. 3. pp. 268-281.

Berná, Z., Špalek, J. (2009), "Přispívání na veřejný statek: svádí neosobní kontakt k černému pasažérství?" in Veřejná ekonomika a správa 2009: Sborník abstraktů z mezinárodní konference. 1. vydání. Ostrava : VŠB-TUO, Ekonomická fakulta, 2009. ISBN 978-80-248-2049-1.

Brock, J. R. A. (1991), "Public Goods Experiment for the Classroom.” Economic Inquiry, 29(2); pp. 395-401. 
Chaudhuri, A. (2007), Conditional Cooperation and Social Norms in Public Goods Experiments: A Survey of the Literature. Unpublished Manuscript, University of Auckland, August 2007.

Croson, R., Marks, M. (2000), "Step Returns in Threshold Public Goods: A Meta - and Experimental Analysis." Experimental Economics, Vol. 3, pp.239 - 259.

Dale, D. (2004), "Charitable Lottery Structure and Fund Raising: Theory and Evidence." Experimental Economics, Vol. 7, pp. 217-234.

Davis, D., Holt, Ch. (1993), Experimental Economics. New Jersey: Princeton University Press, 1993. p. 572. ISBN 0-691-04317-5.

Fischbacher, U. (2007), "Z-Tree: Zurich Toolbox for Ready-made Economic Experiments." Experimental Economics 10(2), pp. 171-178.

Frank, R., Gilovich, T., Regan, D. (1993), “Does Studying Economics Inhibit Cooperation?” The Journal of Economic Perspectives. Vol. 7, No. 2, pp. 159-171.

Holt, Ch. (2007), A Markets, Games, and Strategic Behavior. Boston : Pearson Addison Wesley, 2007. ISBN: 032141931.

Huck, S, Rasul, I. (2008), "Comparing Charitable Fundraising Schemes: Evidence from a Natural Field Experiment." Working paper. ELSE Working Papers (274). ESRC Centre for Economic Learning and Social Evolution, London, UK.

Isaac, R. M., Mccue, K. F., Plott, C. R. (1985), "Public Goods Provision in an Experimental Environment." Journal of Public Economics. Vol. 26, No. 1, pp. 51-74.

Ledyard, J. (1995). "Public Goods: A Survey of Experimental Research," in J. H. Kagel and A. E. Roth (eds.), Handbook of Experimental Economics. Princeton, Princeton University Press, pp. 111-194.

Marks, M., Lehr, D., Brastoe, R. (2003), "Cooperation versus Free-Riding in a Threshold Public Goods Setting: A Clasroom Experiment." (February 24, 2003). Available at http://ssrn.com/ abstract $=385380$.

Marwell, G., Ames, R. E. (1979), "Experiments on the Provision of Public Goods. I. Resources, Interest, Group Size, and the Free-Rider Problem." The American Journal of Sociology. Vol. 84, No. 6, pp. 1335-1360.

Marwell, G., Ames, R. E. (1980), "Experiments on the Provision of Public Goods. II. Provision Point, Stakes, Experience, and the Free-Rider Problem." The American Journal of Sociology. Vol. 85, No. 4, pp. 926-937.

Mcbride, M. (2006), "Discrete Public Goods under Threshold Uncertainty: Theory and Experiment." Journal of Public Economics. Vol. 90, No. 6-7, pp.1181-1199.

Plott, Ch., Smith, V. (2008), Handbook of Experimental Economics Results. 1st Ed. Amsterdam: North-Holland, 2008. 109731 s. ISBN 9780444826428.

Rondeau, D., List, J. A. (2008), “The Impact of Challenge Gifts on Charitable Giving: an Experimental Investigation." Economics Letters, Vol. 79, No. 2, pp. 153-159.

Šeneklová, J., Špalek, J. (2009), “Jsou ekonomové jiní? Ekonomický model versus realita." Politická ekonomie. Vol. 57, No. 1, pp. 21-45.

Špalek, J., Darmopilová, Z., Pavlík, M., Špalková, D. (2008), “Dobrovolné přispívání na veřejný statek: Jsou čeští studenti jiní?" in Bílá místa teorie a černé díry reforem ve veřejném sektoru. 1. vyd. Brno: Masarykova univerzita, pp. 222-235.

Yezer, A., Goldfarb, R., Poppen, P. (1996), "Does Studying Economics Discourage Cooperation? Watch What We Do, Not What We Say or How We Play." The Journal of Economic Perspectives, Vol. 10, No. 1, pp. 177-186.

Zelmer, J. (2003), "Linear Public Goods Experiments: A Meta-Analysis." Experimental Economics, 6(3), pp. 299-310. 